\title{
Association between the blood concentrations of ammonia and carnitine/ amino acid of schizophrenic patients treated with valproic acid
}

\author{
Masazumi Ando ${ }^{1,2,4^{*}}$, Hideaki Amayasu ${ }^{3}$, Takahiro Itai $^{3}$ and Hisahiro Yoshida ${ }^{1}$
}

\begin{abstract}
Background: Administration of valproic acid (VPA) is complicated with approximately $0.9 \%$ of patients developing hyperammonemia, but the pathogenesis of this adverse effect remains to be clarified. The aim of the present study was to search for mechanisms associated with VPA-induced hyperammonemia in the light of changes in serum amino acids concentrations associated with the urea cycle of schizophrenic patients.

Method: Blood samples $(10 \mathrm{~mL}$ ) were obtained from 37 schizophrenic patients receiving VPA for the prevention of violent behaviors in the morning after overnight fast. Blood concentrations of ammonia, VPA, free carnitine, acyl-carnitine, and 40 amino acids including glutamate and citrulline were measured for each patient. Univariate and multivariate regression analyses were performed to identify amino acids or concomitantly administered drugs that were associated with variability in the blood concentrations of ammonia.

Result: The blood ammonia level was positively correlated with the serum glutamate concentration $(r=0.44, p<0.01)$ but negatively correlated with glutamine $(r=-0.41, p=0.01)$, citrulline $(r=-0.42, p=0.01)$, and glycine concentrations $(r=-0.54, p<0.01)$. It was also revealed that the concomitant administration of the mood stabilizers $(p=0.04)$ risperidone $(p=0.03)$ and blonanserin $(p<0.01)$ was positively associated with the elevation of the blood ammonia level.

Conclusion: We hypothisized that VPA would elevate the blood ammonia level of schizophrenic patients. The observed changes in serum amino acids are compatible with urea cycle dysfunction, possibly due to reduced carbamoyl-phosphate synthase 1 (CPS1) activity. We conclude that VPA should be prudently prescribed to schizophrenic patients, particularly those receiving mood stabilizers or certain antipsychotics.
\end{abstract}

Keywords: Hyperammonemia, Valproic acid, Carnitine, Glutamate, Glycine, CPS1, Mood stabilizer, Antipsychotics

\section{Background}

Valproic acid (VPA) is widely used for the treatment of generalized or partial epilepsy (e.g., absent seizures, tonic-clonic seizures) [1]. Recently, VPA has also been prescribed to patients with various psychological diseases, because it has been shown to be effective for ameliorating or preventing violent behaviors by patients

\footnotetext{
* Correspondence: m_ando@tmg.or.jp

'Department of Drug Metabolism and Disposition, Meiji Pharmaceutical University, 2-522-1 Noshio, Kiyose, Tokyo 204-8588, Japan

${ }^{2}$ Department of Pharmacy, Heartful Kawasaki Hospital, 2-1-3 Shimonoge,

Takatsu-ku, Kawasaki, Kanagawa 213-0006, Japan

Full list of author information is available at the end of the article
}

with bipolar disorder, manic psychosis, and sometimes patients with schizophrenia [1]. It has been reported that one-third or more of schizophrenia patients admitted to hospitals are given VPA or other mood stabilizers in Japan [2] and the USA [3].

Hyperammonemia is a rare but severe adverse reaction associated with the administration of VPA. Clinical symptoms of VPA-induced hyperammonemia can range from mild disturbance of consciousness to coma [4-6]. At present, the etiology or pathogenesis of VPA-induced hyperammonemia is understood only partially. Briefly, VPA, a branched-chain carboxylic acid, is metabolized 
mainly by glucuronide conjugation in the cytosol, but it also undergoes $\beta$-oxidation in the mitochondria. VPA and other branched-chain fatty acids are transported into mitochondria via a common transporter of which activity is facilitated by conjugation with carnitine (Fig. 1) $[7,8]$. Thus, when patients receive VPA the transport of carnitine-conjugated VPA into mitochondria may interfere with the transport of other fatty acids and thereby attenuate mitochondrial production of acetyl-CoA by the $\beta$-oxidation of fatty acids. Acetyl-CoA and glutamate are metabolized to $\mathrm{N}$-acetyl glutamic acid (NAG) by $\mathrm{N}$-acetyl glutamic acid synthase (NAGS) [9]. NAG is known to augment the activity of carbamoyl-phosphate synthase 1 (CPS1) by an allosteric mechanism [10]. Because ammonia is metabolized to carbamoyl phosphate by CPS1 and then enters the urea cycle, the VPA-induced attenuation of CPS1 activity may have a detrimental effect on ammonia metabolism.

Previous studies have reported that the administration of therapeutic doses of VPA to patients with epilepsy or bipolar disorder can cause hyperammonemia and alter serum carnitine and amino acid concentrations [11-14], whereas no attempts have been made to determine if VPA causes hyperammonemia when administered to patients with schizophrenia. Here, we report the relationships between blood ammonia concentration and the concentrations of free carnitine, acyl-carnitine, and amino acids, including glutamate and citrulline, in a cohort of schizophrenic patients receiving VPA. We hope to shed light on the mechanism of VPA-induced hyperammoninemia.

\section{Methods}

\section{Participants}

Schizophrenic patients who were admitted to Heartful Kawasaki Hospital between January 2013 and February 2014 participated in the present study after voluntarily giving written consent. The study protocol was approved by the Ethics Review Board of Meiji Pharmaceutical University (Approval No.: 2403). To protect patient privacy, personal information was carefully handled.

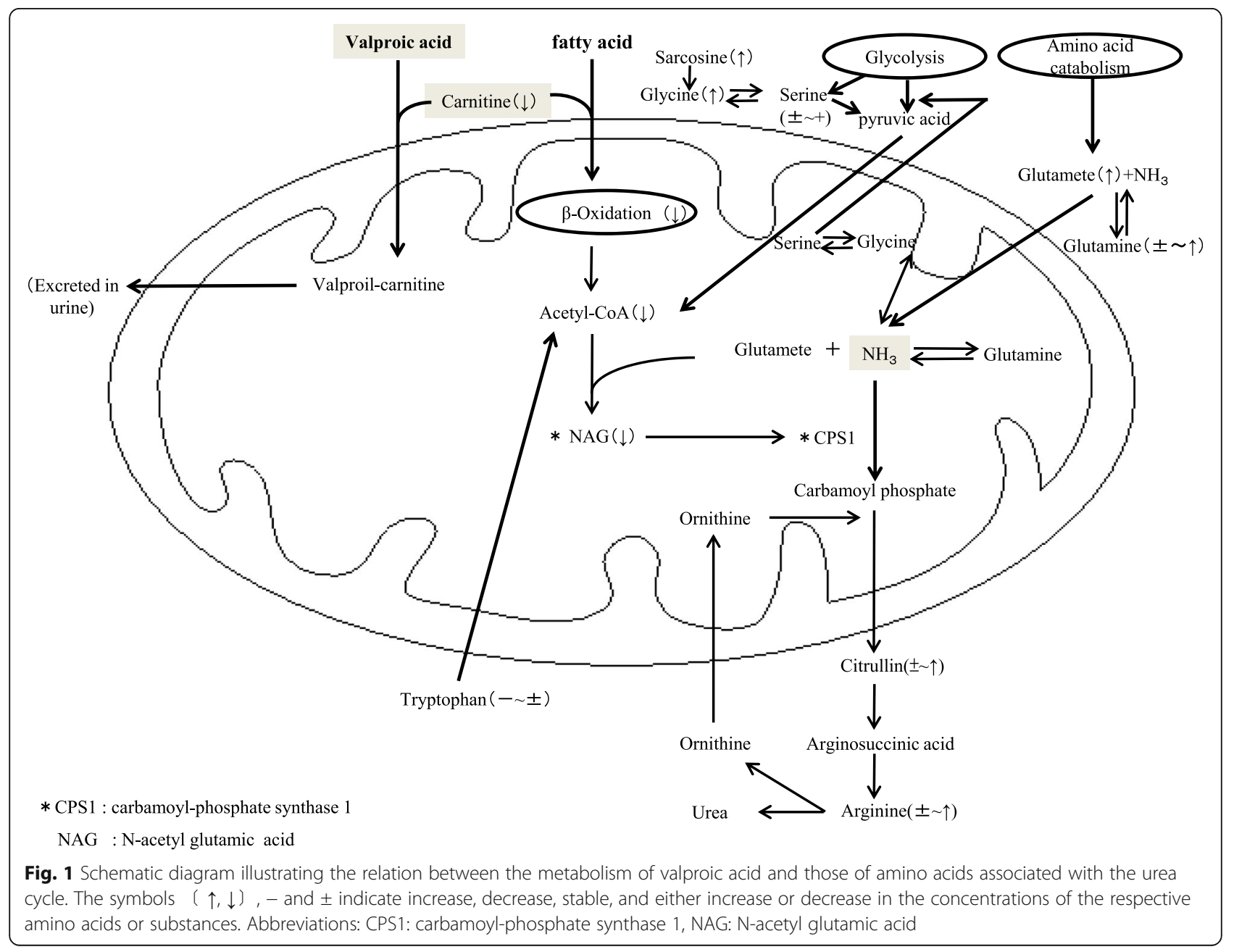




\section{Blood collection and measurements}

Venous blood $(10 \mathrm{~mL})$ was collected in the morning after an overnight fast, before the administration of VPA. A portion of the sample was transferred to the clinical laboratory of our hospital for routine biochemical tests, and the remaining was divided into two samples. One was transferred to BML Co., Ltd. for determination of the blood ammonia concentration and the serum concentrations of free carnitine, acyl-carnitine, and 40 amino acids, including glutamate and citrulline. The other was transferred to the Pharmacokinetics Laboratory, Meiji Pharmaceutical University for determination of the serum VPA concentration. Briefly, blood samples were centrifuged at $3000 \mathrm{rpm}$ for five minutes to isolate serum, which was then frozen and stored until measurement. For serum VPA analysis, a 5-fold volume of methanol was added to serum isolated from patients, mixed, rested for 30 to $40 \mathrm{~min}$, and centrifuged at $12,000 \mathrm{rpm}$ for $1 \mathrm{~min}$ for deproteinization. VPA was assayed with high-performance liquid chromatography (HPLC) with mass spectrometry (LC-MS) detection using the LC-MS 2020 system (Shimadzu, JAPAN). Assay conditions were as follows: column, C180DS $(2 \times 50 \mathrm{~mm})$; mobile phase, a solution consisting of $20 \mathrm{mM}$ ammonium formate and acetonitrile; flow velocity, $0.2 \mathrm{~mL} / \mathrm{min}$; mode of analysis, SIM measurement; and range of analysis, $\mathrm{m} / \mathrm{z} 143.3$.

\section{Statistical analysis}

Because we did not measure the amino acid concentrations of healthy subjects, we adopted the reference ranges of the respective amino acids that were established for healthy subjects by the laboratory of BML Co. Ltd. Multivariate regression analysis was conducted to determine if any of the serum amino acids and other substrates are significant covariates of blood ammonia concentration. Analysis was also conducted to determine if the administration of mood stabilizers or antipsychotics as a group would be associated with the variability of blood ammonia concentration. We also conducted a multivariate regression analysis to examine whether or not any of the individual antipsychotics would exert an independent influence on the variability of the blood concentration of ammonia. Multivariate regression analysis was performed using JMP $\mathrm{JP}^{\circ}$ software (ver. 11). A $p$-value of less than 0.05 was considered statistically significant.

\section{Results}

Thirty-seven schizophrenic patients (24 male and 13 female aged from 37 to 77 years) who received VPA participated in the present study. Their body weights ranged from 34 to $82 \mathrm{~kg}$, and the mean $( \pm \mathrm{SD})$ dose of VPA was $12 \pm 5 \mathrm{mg} / \mathrm{kg}$, equivalent to $1481 \pm 1347 \mathrm{mg} /$ day of chlorpromazine [15]. All patients consumed a regular hospital diet consisting of adequate amounts of calorie, protein and vitamins. Table 1 shows the blood concentrations of ammonia, aspartate transaminase (AST), alanine transaminase (ALT), and VPA. Elevation of the laboratory data exceeding $30 \%$ or greater than the upper limits of the respective reference ranges was considered clinically significant. While $30 \%$ of the patients showed clinically significant elevation of blood ammonia, less than $11 \%$ of them showed clinically meaningful elevation of AST or ALT. Ninety-five percent of the patients had serum VPA concentration within the therapeutic range.

Table 2 shows the serum concentration of amino acids and related constituents that were measured in the present study. Using the reference values, we assessed whether or not the serum amino acid profiles of patients receiving VPA would be altered as compared to those of healthy subjects. A considerable percentage of patients showed serum concentrations of several amino acids that were 1.3-times greater than the upper limit of the reference ranges: glutamate $(68 \%)$, glutamine $(38 \%)$, glycine (38\%), $\alpha$-amino-n-butyric acid (70\%), cystathionine $(73 \%)$, and taurine (35\%). In contrast, the serum concentrations of free carnitine, acyl-carnitine, and tryptophan were reduced as compared to the respective reference ranges. Univariate regression analysis revealed that the blood concentration of ammonia was correlated positively with that of glutamate $(r=0.44, p<0.01)$ and tryptophan $(r=0.35, p=0.03)$. Conversely, the blood concentration of ammonia was correlated negatively with that of glutamine $(r=-0.41, p=0.01)$, citrulline $(r=-0.42, p=0.01)$, and glycine $(r=-0.54, p<0.01)$.

Table 3 shows the results of multivariate regression analysis conducted to identify significant covariates for blood ammonia concentration. The results indicated that the blood concentration of ammonia was positively correlated with that of glutamate $(p<0.01)$, valine $(p<0.01)$, and cysteine $(p=0.04)$ but negatively correlated with that of $\alpha$-amino-n-butyric acid $(p<0.01)$, ethanolamine $(p<0.01)$, and 3-methylhistidine $(p<0.01)$.

Table 4 shows the results of the multivariate regression analysis conducted to examine whether or not the administration of mood stabilizers or antipsychotics with VPA would be associated with variability of blood ammonia concentration. All patients were given antipsychotic drugs and mood stabilizers. When we examined whether or not the administration of mood stabilizers or antipsychotics as a group had an influence on blood ammonia concentration, the administration of mood stabilizers $(p=0.04)$, but not antipsychotics, augmented blood ammonia concentration. However, when we evaluated the independent contribution of each drug with a multivariate regression analysis, we found that only risperidone $(p=0.03)$ and blonanserin $(p<0.01)$ were significantly associated with elevation of the blood concentration of ammonia (Table 5). 
Table 1 Mean $( \pm S D)$ values for blood ammonia concentration, VPA doses, and liver function as well as percentage of patients exhibiting clinically significant elevations of the respective laboratory data

\begin{tabular}{|c|c|c|c|c|c|}
\hline \multirow[t]{2}{*}{ constituent } & \multirow[t]{2}{*}{ Unit } & \multicolumn{4}{|l|}{ Total $(n=37)$} \\
\hline & & Reference range & Mean \pm SD of patients & Below Reference range \% & $\begin{array}{l}\text { Patients exhibiting values } \\
\text { of } 1.3 \text {-times or greater than } \\
\text { the upper limits of the } \\
\text { reference range (\%) }\end{array}$ \\
\hline ammonia & $\mu \mathrm{g} / \mathrm{dL}$ & $18-70$ & $64 \pm 19$ & 0 & 30 \\
\hline AST & $\mathrm{IU} / \mathrm{L}$ & $7-38$ & $21 \pm 7$ & 0 & 5 \\
\hline ALT & IU/L & $4-44$ & $23 \pm 15$ & 0 & 11 \\
\hline VPA concentration & $\mu \mathrm{g} / \mathrm{mL}$ & $50-100$ & $51 \pm 24$ & 54 & 5 \\
\hline
\end{tabular}

Abbreviations: AST Aspartate transaminase, ALT Alanine transaminase, VPA valproic acid

Scrutinizing the concomitant medications of the 37 schizophrenic patients who participated in the study, it was found that none had received corticosteroids or amino acids or were suffering from malnutrition.

\section{Discussion}

In the present study, we revealed that about one-third of the schizophrenic patients receiving VPA showed an elevated blood ammonia concentration: $30 \%$ of the patients showed a blood ammonia level of 1.3 times or higher than the upper limit of the reference values (Table 1). In addition, $68 \%, 38 \%$, and $38 \%$ of the participants showed a clinically significant elevations of the serum concentration of glutamate, glutamine, and glycine, respectively (Table 2). In addition, there was a positive correlation between the blood concentrations of glutamate and ammonia (Table 3). Conversely, there were negative correlations between the blood ammonia concentration and that of glutamine and glycine (Table 3). In addition, $41 \%$ of the patients showed a reduced serum free carnitine concentration below the lower limit of the reference range. These findings appear largely compatible with the hypothesis that reduced serum carnitine concentration can be attributed to the augmented consumption of carnitine by conjugation with VPA and transport into mitochondria. If the cytosolic carnitine pool available for the transport of other branched chain fatty acids is depleted by VPA, the $\beta$-oxidation of these fatty acids and resultant production of acetyl-CoA might have been impaired. Consequently, the production of NAG from acetyl-CoA and glutamate might also have been impaired $[7,8]$. The significant elevation of the serum glutamate level might have been due to an attenuated production of NAG from acetyl-CoA and glutamate. Because NAG stimulates the activity of carbamoylphosphate synthase 1 (CPS1), which is a key enzyme of the ATP-dependent synthesis of carbamoyl phosphate from ammonia or glutamine and bicarbonate [10], the shortage of NAG would impair the subsequent reactions in the urea cycle.
The idea that VPA inhibits the activity of carbamoylphosphate synthase I (CPS1) was proposed for the first time in literature by Vazquez and others [16]. They studied the VPA-induced hyperammonemia of 11 pediatric patients with epilepsy only in the light of altered plasma concentrations of carnitine and acetylcarnitine. In the present study, however, we studied the alerted ammonia metabolism of patients receiving VPA not only in the light of changes in the carnitine/acetylcarnitine concentration but also of other amino acids that might also be involved in altered ammonia metabolism. In this context, the present study has expanded and deepened the original concept of the inhibitory effects of VPA on the activity of CPS1 and hyperammonemia.

We performed multivariate regression analysis to investigate the influence of the dose and plasma concentrations of VPA, free carnitine, acyl-carnitine, and six other amino acids on the blood concentration of ammonia (Table 3). No significant correlations were observed between the blood ammonia level and the VPA dose or, serum concentration of VPA, free carnitine, and acylcarnitine. This finding contradicts that of a previous study [17], but was consistent with others [18, 19]. At present, reports on the relation between the plasma concentrations of VPA and ammonia are conflicting, In contrast, the serum concentrations of cysteine, ethanolamine, glutamate, valine, glutamate, $\alpha$-amino-n-butyric acid, and 3-methyl-histidine were significantly correlated with blood ammonia concentration. Of them, glutamate had the greatest contribution among other factors to the variability of blood ammonia concentration. Alterations in serum cysteine and valine concentration may have been influenced by elevated glutamate concentration, because glutamate is synthesized by tansamination of these amino acids by glutamate- $\alpha$ ketoglutaric acid at the time of catabolism (Fig. 1) [20].

While the genetic polymorphism of CPS1 is associated with reduced enzyme activity [21, 22], concomitantly administrated medications, such as antiepileptic drugs with enzyme inducing property (e.g., carbamazepine, phenobarbital, phenytoin), were shown to alter CPS1 activity [10]. Previous studies have suggested that the 
Table 2 Serum concentrations of amino acids, free carnitine, acyl-carnitine obtained from patients and the respective reference ranges, as well as the correlations of their concentrations with blood ammonia concentrations

\begin{tabular}{|c|c|c|c|c|c|c|c|}
\hline \multirow[t]{2}{*}{ constituent } & \multirow[t]{2}{*}{ Unit } & \multicolumn{4}{|l|}{ Total $(n=37)$} & \multicolumn{2}{|c|}{ correlation coefficient } \\
\hline & & Reference range & Mean \pm SD & $\begin{array}{l}\text { Patients exhibiting } \\
\text { below the lower } \\
\text { limits of the reference } \\
\text { range (\%) }\end{array}$ & $\begin{array}{l}\text { Patients exhibiting values } \\
\text { of } 1.3 \text {-times or greater } \\
\text { than the upper limits of } \\
\text { the reference range (\%) }\end{array}$ & $r$ value & $p$ value \\
\hline Free Carnitine & $\mu \mathrm{mol} / \mathrm{L}$ & $36-74$ & $33 \pm 13$ & 41 & 0 & 0.02 & 0.91 \\
\hline Acyl-Carnitine & $\mu \mathrm{mol} / \mathrm{L}$ & $6-23$ & $8 \pm 4$ & 38 & 0 & -0.24 & 0.15 \\
\hline 1-Methyl-histidine & $\mathrm{nmol} / \mathrm{mL}$ & $<9.1$ & $5 \pm 5$ & 0 & 8 & -0.09 & 0.66 \\
\hline 3-Methyl-histidine & $\mathrm{nmol} / \mathrm{ml}$ & TRA-8.2 & $4 \pm 2$ & 0 & 5 & -0.30 & 0.08 \\
\hline Alanine & $\mathrm{nmol} / \mathrm{mL}$ & 258.8-615.2 & $458 \pm 130$ & 3 & 8 & 0.24 & 0.15 \\
\hline Anserine & $\mathrm{nmol} / \mathrm{ml}$ & ND & ND & 0 & 0 & - & - \\
\hline Arginine & $\mathrm{nmol} / \mathrm{mL}$ & $31.8-149.5$ & $128 \pm 32$ & 0 & 27 & -0.27 & 0.10 \\
\hline Asparagine & $\mathrm{nmol} / \mathrm{ml}$ & 43.8-90.6 & $56 \pm 11$ & 19 & 0 & -0.23 & 0.17 \\
\hline Aspartic acid & $\mathrm{nmol} / \mathrm{mL}$ & TRA-7.2 & $5 \pm 2$ & 0 & 5 & 0.08 & 0.63 \\
\hline Carnosine & $\mathrm{nmol} / \mathrm{mL}$ & ND & ND & 0 & 0 & - & - \\
\hline Citrulline & $\mathrm{nmol} / \mathrm{mL}$ & $17.9-48.0$ & $45 \pm 12$ & 0 & 27 & -0.42 & $0.01^{*}$ \\
\hline Cystathionine & $\mathrm{nmol} / \mathrm{mL}$ & ND & $2 \pm 0$ & 0 & 73 & -0.09 & 0.66 \\
\hline Cystin & $\mathrm{nmol} / \mathrm{mL}$ & $4.7-34.8$ & $19 \pm 11$ & 3 & 14 & -0.25 & 0.14 \\
\hline Ethanolamine & $\mathrm{nmol} / \mathrm{mL}$ & TRA-10.5 & $7 \pm 2$ & 0 & 3 & 0.15 & 0.37 \\
\hline Glutamate & $\mathrm{nmol} / \mathrm{mL}$ & $12.2-82.7$ & $122 \pm 59$ & 0 & 68 & 0.44 & $\left\langle 0.01^{*}\right.$ \\
\hline Glutamine & $\mathrm{nmol} / \mathrm{mL}$ & 418.0-739.8 & $700 \pm 128$ & 0 & 38 & -0.41 & 0.01 \\
\hline Glycine & $\mathrm{nmol} / \mathrm{mL}$ & $140.4-427.3$ & $394 \pm 102$ & 0 & 38 & -0.54 & $\left\langle 0.01^{*}\right.$ \\
\hline Hdroxylysine & $\mathrm{nmol} / \mathrm{mL}$ & ND & ND & 0 & ND & - & - \\
\hline Histidine & $\mathrm{nmol} / \mathrm{mL}$ & 63.0-105.2 & $94 \pm 15$ & 0 & 27 & 0.00 & 0.99 \\
\hline Homocystine & $\mathrm{nmol} / \mathrm{mL}$ & ND & ND & 0 & 0 & - & - \\
\hline Hydroxyproline & $\mathrm{nmol} / \mathrm{mL}$ & TRA-18.8 & $17 \pm 5$ & 0 & 27 & -0.30 & 0.10 \\
\hline Isoleucine & $\mathrm{nmol} / \mathrm{mL}$ & $37.0-100.4$ & $78 \pm 15$ & 0 & 8 & -0.07 & 0.67 \\
\hline Leucine & $\mathrm{nmol} / \mathrm{mL}$ & 74.2-169.1 & $134 \pm 25$ & 0 & 8 & 0.05 & 0.76 \\
\hline Lysine & $\mathrm{nmol} / \mathrm{mL}$ & $125.7-281.9$ & $237 \pm 44$ & 0 & 22 & -0.30 & 0.08 \\
\hline Methionine & $\mathrm{nmol} / \mathrm{mL}$ & $15.5-38.6$ & $30 \pm 5$ & 0 & 8 & -0.14 & 0.40 \\
\hline Ornithine & $\mathrm{nmol} / \mathrm{mL}$ & $42.6-141.2$ & $86 \pm 25$ & 0 & 3 & -0.05 & 0.78 \\
\hline Phenylalanine & $\mathrm{nmol} / \mathrm{mL}$ & $43.5-79.8$ & $59 \pm 9$ & 0 & 3 & 0.02 & 0.91 \\
\hline Phosphoethanol-amine & $\mathrm{nmol} / \mathrm{mL}$ & TRA & TRA & 0 & 0 & - & - \\
\hline Proline & $\mathrm{nmol} / \mathrm{mL}$ & $71.3-373.0$ & $289 \pm 241$ & 0 & 11 & -0.16 & 0.36 \\
\hline Sarcosine & $\mathrm{nmol} / \mathrm{mL}$ & TRA & $8 \pm 3$ & 0 & 51 & -0.34 & 0.15 \\
\hline Serine & $\mathrm{nmol} / \mathrm{mL}$ & $91.5-186.4$ & $168 \pm 34$ & 0 & 24 & -0.04 & 0.81 \\
\hline Taurine & $\mathrm{nmol} / \mathrm{mL}$ & $46.4-128.2$ & $110 \pm 43$ & 3 & 35 & -0.15 & 0.37 \\
\hline Threonine & $\mathrm{nmol} / \mathrm{mL}$ & $74.2-216.1$ & $144 \pm 35$ & 0 & 3 & -0.15 & 0.39 \\
\hline Tryptophan & $\mathrm{nmol} / \mathrm{mL}$ & $36.2-79.3$ & $37 \pm 10$ & 59 & 0 & 0.35 & $0.03^{*}$ \\
\hline Tyrosine & $\mathrm{nmol} / \mathrm{mL}$ & 38.4-89.4 & $72 \pm 18$ & 0 & 16 & 0.18 & 0.28 \\
\hline Valine & $\mathrm{nmol} / \mathrm{mL}$ & $156.2-360.4$ & $248 \pm 41$ & 0 & 0 & -0.02 & 0.89 \\
\hline a-aminoadipic acid & $\mathrm{nmol} / \mathrm{mL}$ & ND & ND & 0 & 0 & - & - \\
\hline a-amino-n-butyric acid & $\mathrm{nmol} / \mathrm{mL}$ & $8.1-31.0$ & $35 \pm 8$ & 0 & 70 & -0.10 & 0.06 \\
\hline
\end{tabular}


Table 2 Serum concentrations of amino acids, free carnitine, acyl-carnitine obtained from patients and the respective reference ranges, as well as the correlations of their concentrations with blood ammonia concentrations (Continued)

\begin{tabular}{|c|c|c|c|c|c|c|c|}
\hline$\beta$-Alanine & $\mathrm{nmol} / \mathrm{mL}$ & TRA-11.8 & $2 \pm 1$ & 0 & 0 & 0.05 & 0.88 \\
\hline$\beta$-Amino-iso-butyric acid & $\mathrm{nmol} / \mathrm{mL}$ & $<5.9$ & $3 \pm 2$ & 0 & 5 & -0.18 & 0.32 \\
\hline Y-Amino-nbutyric acid & $\mathrm{nmol} / \mathrm{mL}$ & ND & ND & 0 & 0 & - & - \\
\hline
\end{tabular}

The correlation between the concentration of ammonia and each item is presented. A $p$-value of 0.05 was regarded as significant

TRA Trace

ND Not detectable

*: $p<0.05$

concomitant use of VPA with an antipsychotic, risperidone, may be a risk factor for hyperammonemia through competition for drug protein binding [11-13]. However, it remains to be clarified whether or not the combination of certain antipsychotics reduces CPS1 activity. Since the schizophrenia patients investigated in this study received both antipsychotics and mood stabilizers, we performed a multivariate analysis to study whether or not the coadministration of these drugs would have affected the blood ammonia concentration. The results indicated that the concomitant administration of mood stabilizers is associated with increased blood ammonia concentration, but that the administration of antipsychotics as a whole is not (Table 4). VPA had been administered to all patients, some of whom were receiving lithium $(n=5)$ or carbamazepine $(n=5)$. Because the 17 different antipsychotics prescribed are quite different in physicochemical and pharmacological properties, we undertook a multivariate analysis to determine if any of them independently influenced the blood ammonia level (Table 5). We found that concomitant administration of risperidone or blonanserin was associated with a reduced blood concentration of ammonia, which somewhat conflicts with the results reported by previous studies [11-13], our data will need to be confirmed in a study with a larger number of patients: the

Table 3 Results of multivariate regression analysis performed for identifying significant covariates of blood ammonia concentrations

\begin{tabular}{lllll}
\hline constituent & Unit & \multicolumn{3}{l}{ Total $(n=37)$} \\
\cline { 3 - 5 } & & Estimate & $F$ value & $p$ value \\
\hline Dose of VPA & $\mathrm{mg} / \mathrm{day}$ & 0 & 0.53 & 0.49 \\
VPA concentration & $\mu \mathrm{g} / \mathrm{mL}$ & 0 & 1.13 & 0.32 \\
Free Carnitine & $\mu \mathrm{mol} / \mathrm{L}$ & 0 & 0.14 & 0.72 \\
Acyl-Carnitine & $\mu \mathrm{mol} / \mathrm{L}$ & 0 & 0.07 & 0.80 \\
Cysteine & $\mathrm{nmol} / \mathrm{mL}$ & 0.26 & 6.01 & $0.04^{*}$ \\
Ethanolamine & $\mathrm{nmol} / \mathrm{mL}$ & -5.45 & 21.03 & $<0.01^{*}$ \\
Glutamate & $\mathrm{nmol} / \mathrm{mL}$ & 0.15 & 34.07 & $<0.01^{*}$ \\
Valine & $\mathrm{nmol} / \mathrm{mL}$ & 0.09 & 14.46 & $<0.01^{*}$ \\
a-amino-n-butyric acid & $\mathrm{nmol} / \mathrm{mL}$ & -0.49 & 19.79 & $<0.01^{*}$ \\
3-metyl-Histidine & $\mathrm{nmol} / \mathrm{mL}$ & -1.57 & 20.63 & $<0.01^{*}$ \\
\hline VPA: valproic acid & & & & \\
*: $p<0.05$ & & & &
\end{tabular}

number of patients receiving blonanserin with VPA was small $(n=3)$ in the present study.

There is a possibility that other drugs administered for the treatment of non-psychiatric diseases (e.g., corticosteroids) or the poor nutritional status of the patients might influence the blood ammonia concentration [23-26]. However, none of our patients received corticosteroids. In addition, they orally consumed a standard hospital diet and received no parenteral amino acid supplementation. Because ammonia is metabolized by the urea cycle in the liver, liver dysfunction might have been associated with an increase in the blood concentration of ammonia. However, none of the patients had severe liver dysfunction (Table 1), therefor it would be only a remote possibility that liver dysfunction was associated with our findings. We found that the serum levels of glutamate and glycine were elevated in this cohort of schizophrenic patients receiving VPA. Because glutamate is an agonist of N-methyl-D-aspartate (NMDA) receptors in the cerebral excitatory nerves and glycine is a co-agonist of NMDA receptors [27], the administration of VPA might have offset the therapeutic effects necessary for the prevention of violent behaviors by these patients.

Currently, VPA is frequently used for ameliorating and/or preventing the violent behaviors of patients with schizophrenia [1-3]. The effects of VPA on blood ammonia concentration observed for schizophrenic patients are largely compatible with those reported for patients with other psychiatric disorders and for those with epilepsy [10-14]. However, caution should be exercised in drawing conclusions, because there are substantial differences in the VPA dose, concomitant medications, and the genetic background of the two groups of patients. For patients with chronic schizophrenia receiving VPA, dose-reduction or discontinuation is not often discussed, whether or not violent behaviors have been observed. As

Table 4 Influence of the number of antipsychotics or mood stabilizers on the concentration of ammonia (regression analysis)

\begin{tabular}{lllll}
\hline & \multicolumn{4}{l}{ Total $(n=37)$} \\
\cline { 2 - 5 } & $\mathrm{N}$ & Estimate & F value & $p$ value \\
\hline Antipsychotic drug & 37 & 0 & 0.62 & 0.44 \\
Mood stabilizer & 37 & 12.94 & 4.66 & $0.04^{*}$ \\
\hline$*: p<0.05$ & & &
\end{tabular}


Table 5 The results of multivariate regression analysis exhibiting the influence of individual antipsychotics on blood ammonia concentrations

\begin{tabular}{lllll}
\hline & \multicolumn{4}{l}{ Total $(n=37)$} \\
\cline { 2 - 5 } & $\mathrm{N}$ & Estimate & F value & $p$ value \\
\hline zotepine & 22 & 0 & 1.06 & 0.31 \\
haloperidol & 18 & 0 & 0.21 & 0.65 \\
chlorpromazine & 18 & 0 & 0.66 & 0.42 \\
risperidone & 13 & -6.70 & 5.17 & $0.03^{*}$ \\
fluphenazine & 10 & 0 & 0.11 & 0.75 \\
levomepromazine & 6 & 0 & 0.77 & 0.39 \\
sultopride & 5 & -7.46 & 3.35 & 0.77 \\
olanzapine & 5 & 0 & 0.05 & 0.83 \\
quetiapine & 5 & 0 & 0.14 & 0.71 \\
nemopride & 4 & 0 & 0.05 & 0.82 \\
aripiprazole & 4 & 0 & 1.15 & 0.29 \\
bromperidol & 3 & 0 & 0.05 & 0.83 \\
blonanserin & 3 & -15.14 & 7.80 & $<0.01^{*}$ \\
propericyazine & 2 & -12.62 & 3.61 & 0.67 \\
perospirone & 2 & 0 & 0.40 & 0.53 \\
pimozide & 1 & 0 & 0.85 & 0.37 \\
paliperidone & 1 & 0 & $<0.01$ & 0.97 \\
\hline *: $p<0.05$ & & & &
\end{tabular}

a result, the patients often receive polypharmacy. There is no evidence that polypharmacy is more effective than monotherapy [28]. The present study revealed that VPA may alter the metabolism of fatty acid and the activity of the urea cycle in such a way that the blood ammonia level is increased in 30\% of the schizophrenic patients. Based upon our data, we feel that it would be prudent to reduce the VPA dose or to discontinue it, if possible. For patients with a previous history of epilepsy, the administration of levocarnitine may be worth trying, because it may activate $\beta$-oxidation and the activity of CPS1, thereby activating the urea cycle and reducing the blood concentration of ammonia [29,30]. We recommend the monitoring of the blood ammonia level of schizophrenic patients receiving VPA.

\section{Conclusions}

In the present study we found that the administration of VPA increased the blood concentrations of ammonia, glutamate, and glycine in some schizophrenic patients receiving mood stabilizers and/or antipsychotics. VPA should be administered carefully to patients with schizophrenia, because it is frequently selected to prevent the appearance of violent behavior. We consider it prudent to refrain from too easily administering VPA to schizophrenic patients for the prevention of violent behaviors.

\section{Abbreviations}

VPA: Valproic acid; NAG: N-acetyl glutamic acid; NAGS: N-acetyl glutamic acid synthase; CPS1: carbamoyl-phosphate synthase 1; NMDA: N-methyl-D-aspartate

\section{Acknowledgements}

We would like to thank our colleagues at the Heartful Kawasaki Hospital Division of Pharmacy for their help in recruiting patients. The authors are also grateful to the participants for their co-operation in the study. We thank Dr. Echizen $\mathrm{H}$ for his help in the editing manuscript. A part of the study was presented at the 26th Annual Meeting of the Japanese of Pharmaceutical Health Care and Sciences, 2016.

\section{Funding}

The authors declare that they received no specific funding

\section{Availability of data and materials}

The datasets generated and/or analyzed in the present study will not be available publicly, because they contain personal information. However, those containing no personal information will be made available by the corresponding author on reasonable request.

\section{Authors' contributions}

$M A, H A$, and $H Y$ planned the study; MA, $\mathrm{Tl}$, and HY performed experiments: MA and HY analyzed the data; MA and HY provided reagents/materials/ analysis tools: MA, HA, and HY wrote the manuscript. All authors read and approved the final version of the manuscript.

\section{Authors' information}

Masazumi Ando worked in the Department of Pharmacy, Heartful Kawasaki Hospital when the present study was conducted and completed. He moved to the Department of Pharmacy, the 2nd Totsuka Kyoritsu Hospital after the submission of the manuscript to BPSM.

\section{Competing interests}

The authors declare that they have no competing interests.

\section{Consent for publication}

The authors declare that all coauthors have given consent for publication

\section{Ethics approval and consent to participate}

The study protocol was approved by the Ethics Review Board (Approval No: 2403) of Meiji Pharmaceutical University. To ensure the security of personal information, we handled it carefully according to the Act for the Protection of Personal Information and the guidelines for the proper handling of personal information by medical and healthcare personnel issued by the Ministry of Health, Welfare, and Labor. Only patients who were able to give written consent by their free will were recruited at Heartful Kawasaki Hospital between January 2013 and February 2014.

\section{Author details}

'Department of Drug Metabolism and Disposition, Meiji Pharmaceutical University, 2-522-1 Noshio, Kiyose, Tokyo 204-8588, Japan. ${ }^{2}$ Department of Pharmacy, Heartful Kawasaki Hospital, 2-1-3 Shimonoge, Takatsu-ku, Kawasaki, Kanagawa 213-0006, Japan. ${ }^{3}$ Division of Psychiatry, Heartful Kawasaki Hospital, 2-1-3 Shimonoge, Takatsu-ku, Kawasaki, Kanagawa 213-0006, Japan. ${ }^{4}$ Department of Pharmacy, the 2nd Totsuka Kyoritsu Hospital, 579-1 Yoshida-cho, Totsuka-ku, Yokohama, Kanagawa 244-0817, Japan.

Received: 11 December 2016 Accepted: 29 May 2017

Published online: 05 July 2017

\section{References}

1. Sadock BJ, Sadock VA. Kaplan and Sadock's pocket handbook of clinical Psychiatry. $2^{\text {nd }}$ ed. Tokyo: Medical Science International; 2003. p.542-545. (Japanese translation).

2. Yoshio T, Inada T, Uno J, Miwa T, Kitagawa K, Miyahara Y, et al. Prescription profiles for pharmacological treatment of Japanese inpatients with schizophrenia: comparison between 2007 and 2009. Hum Psychopharmacol. 2012;27:70-5.

3. Schatzberg AF, Nemeroff CB. The American Psychiatric Publishing textbook of psychopharmacology. 3rd ed. Tokyo; Nishimura Shoten: p. 485-495. (Japanese translation). 
4. Prescribing information of Valerin tablets ${ }^{\circledR}$, Sumitomo Dainippon Pharma Co., Ltd., http://www.info.pmda.go.jp/go/pack/1139004F1045_1_24/. Accessed 20 Feb 2017.

5. Kulick SK, Kramer DA. Hyperammonemia secondary to valproic acid as a cause of lethargy in a postictal patient. Ann Emerg Med. 1993:22:610-2

6. Segura-Bruna N, Rodriguez-Campello A, Puente V, Roquer J. Valproate-induced hyperammonemic encephalopathy. Acta Neurol Scand. 2006;114:1-7.

7. Nakajima Y, Ito T, Maeda Y, Ichiki S, Kobayashi S, Ando N, et al. Evaluation of valproate effects on acylcarnitine in epileptic children by LC-MS/MS. Brain Dev. 2011;33:816-23.

8. Hoppel C. The role of carnitine in normal and altered fatty acid metabolism. Am J Kidney Dis. 2003;41(Suppl 4):S4-12.

9. Aires CC, Cruchten A, ljlst L, Almeida IT, Duran M, Wanders RJ, et al. New insights on the mechanisms of valproate-induced hyperammonemia: inhibition of hepatic $\mathrm{N}$-acetylglutamate synthase activity by valproyl-CoA. J Hepatol. 2011;55:426-34.

10. Tseng YL, Huang CR, Lin CH, Lu YT, Lu CH, Chen NC, et al. Risk factors of hyperammonemia in patients with epilepsy under valproic acid therapy. Medicine (Baltimore). 2014;93:e66.

11. Carlson T, Reynolds CA, Caplan R. Case report: valproic acid and risperidone treatment leading to development of hyperammonemia and mania. J Am Acad Child Adolesc Psychiatry. 2007:46:356-61.

12. Carr RB, Shrewsbury K. Hyperammonemia due to valproic acid in the psychiatric setting. Am J Psychiatry. 2007;164:1020-7.

13. Holroyd S, Overdyke JT. Hyperammonemia associated with valproic acid use in elderly psychiatric patients. J Neuropsychiatr Clin Neurosci. 2012;24:372-4.

14. Werner T, Treiss I, Kohlmueller D, Mehlem P, Teich M, Longin E, et al. Effects of valproate on acylcarnitines in children with epilepsy using ESI-MS/MS Epilepsia. 2007:48:72-6.

15. Inagaki A, Inada T. Dose equivalence of psychotropic drugs. Part XXIV. Dose equivalence of anti-anxiolytics/hypnotics: eszopiclone. Jap J Clin Psychopharmacol. 2012;8:1403-6.

16. Vázquez M, Fagiolino P, Maldonado C, Olmos I, Ibarra M, Alvariza S, et al. Hyperammonemia associated with valproic acid concentrations. Biomed Res Int. 2014;2014:217269.

17. Itoh H, Suzuki Y, Fujisaki K, Sato Y, Takeyama M. Correlation between plasma ammonia level and serum trough concentration of free valproic acid in patients with epilepsy. Biol Pharm Bull. 2012;35:971-4.

18. Williams CA, Tiefenbach S, McReynolds JW. Valproic acid-induced hyperammonemia in mentally retarded adults. Neurology. 1984:34:550-3.

19. Batshaw ML, Brusilow SW. Valproate-induced hyperammonemia. Ann Neurol. 1982;11:319-21.

20. Salway JG. Metabolism at a glance. 2nd ed. Tokyo: Medical Science International; 2012. p. 34-5.

21. Yagi M, Nakamura T, Okizuka Y, Oyazato Y, Kawasaki Y, Tsuneishi S, et al. Effect of CPS1 4217C>a genotype on valproic-acid-induced hyperammonemia. Pediatr Int. 2010;52:744-8.

22. Ono $H$, Suto $T$, Kinoshita $Y$, Sakano T, Furue T, Ohta T. A case of carbamoy phosphate synthetase 1 deficiency presenting symptoms at one month of age. Brain and Development. 2009;31:779-81.

23. York B, Reineke EL, Sagen JV, Nikolai BC, Zhou S, Louet JF, et al. Ablation of steroid receptor coactivator-3 resembles the human CACT metabolic myopathy. Cell Metab. 2012;15:752-63.

24. Gascon-Bayarri J, Campdelacreu J, Estela J, Reñé R. Severe hyperammonemia in late-onset ornithine transcarbamylase deficiency triggered by steroid administration. Case Rep Neurol Med. 2015;2015:453752

25. Dasarathy S, Merli M. Sarcopenia from mechanism to diagnosis and treatment in liver disease. J Hepatol. 2016;65:1232-4.

26. Nakasaki H, Katayama T, Yokoyama S, Tajima T, Mitomi T, Tsuda M, et al. Complication of parenteral nutrition composed of essential amino acids and histidine in adults with renal failure. J Parenter Enter Nutr 1993:17:86-90

27. Tsai GE, Lin PY. Strategies to enhance N-methyl-D-aspartate receptormediated neurotransmission in schizophrenia, a critical review and metaanalysis. Curr Pharm Des. 2010;16:522-37.

28. Galling B, Roldán A, Hagi K, Rietschel L, Walyzada F, Zheng W, et al. Antipsychotic augmentation vs. monotherapy in schizophrenia: systematic review, meta-analysis and meta-regression analysis. World Psychiatry. 2017;16:77-89.

29. Böhles H, Sewell AC, Wenzel D. The effect of carnitine supplementation in valproate-induced hyperammonaemia. Acta Paediatr. 1996:85:446-9.

30. Hamed SA, Abdella MM. The risk of asymptomatic hyperammonemia in children with idiopathic epilepsy treated with valproate: relationship to blood carnitine status. Epilepsy Res. 2009;86:32-41.

\section{Submit your next manuscript to BioMed Central and we will help you at every step:}

- We accept pre-submission inquiries

- Our selector tool helps you to find the most relevant journal

- We provide round the clock customer support

- Convenient online submission

- Thorough peer review

- Inclusion in PubMed and all major indexing services

- Maximum visibility for your research

Submit your manuscript at www.biomedcentral.com/submit 